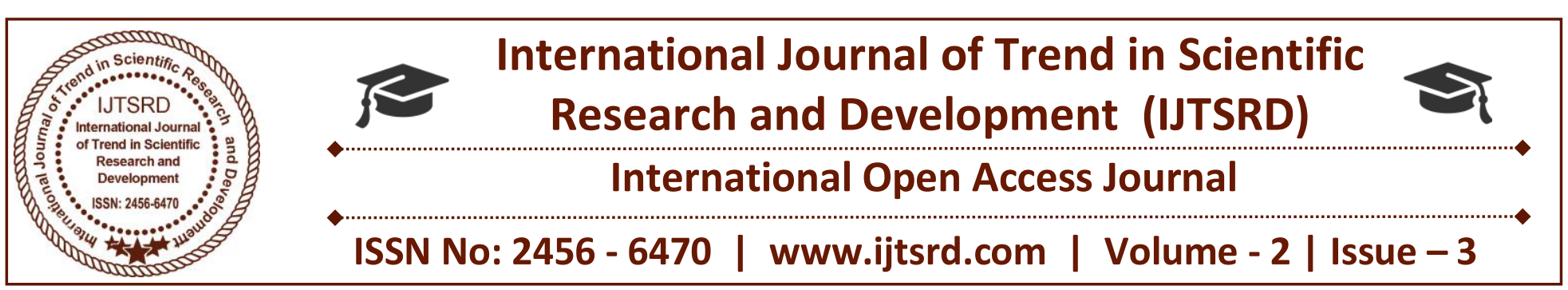

\title{
Aadhar Based Electronic Voting System
}

\author{
Anish. V, Balaji. M, Santhosh Kumar. S \\ Students, Information Technology, Panimalar Institute of Technology, Chennai, India
}

\section{ABSTRACT}

Aadhar based voting for increased productivity and efficiency is one of the primary requirements today for any organization. Our main aim of the proposed system is to develop a compatible voting machine with high security. The proposed system is mainly designed for our country. It has three phases. First the details of the persons who are above 18years are extracted from Aadhar card database since it had become mandatory in present scenario. To ensure more security, finger prints of the voter is used as the main authentication resource. Since the finger pattern of each human being is different, the voter can be easily authenticated. The system allows the voter to vote through his fingerprint. Finger print is used to uniquely identify the user. The finger print minutiae features are different for each human being. Finger print is used as a authentication of the voters. This is done to preserve the security. When people cast their vote the results will be updated automatically and on the same day of election, the results will also be published. Desna Sebastian GreeshmaGopiLiniRajan "Aadhar Based Electronic Voting System and Providing Authentication".In this paper we propose compatible voting that are efficiently implementable using gsm for the security to voters.

\section{INTRODUCTION}

The paper describes the policy with respect to electronic approaches and development towards electronic data transmission and storage. Finger print module for voting machines and different existing identity documents are enforced during this project which can help ballotters to cast the vote in any situation. The Internet of Things has immense potential to change many of our routines, daily activities and behaviors. The pervasive nature of the internet means that a large amount of data regarding to possibly every aspect of public and private will be produced, transmitted, collected and stored. The project deals with the polling machines which uses the biometric validation and cloud storage. It also increases the security provided in the current polling machine. The cloud is secured with the encryption and the decryption techniques we plan to implement this project with the help of Arduino board with the capability to perform the IoT operations. We plan on using Arduino Mega Board to implement this project which is a microcontroller. It has digital input/output pins, analog inputs, crystal oscillator, a USB connection, a power jack, UART and a reset button. It contains everything needed to support the microcontroller, connect it to a computer with a USB cable. The Mega is compatible with most shields designed for the Arduino Duemilanove or Diecimila. The voting system in present days requires a manual registration with a voter id with which voters are allowed to vote. The ballotters can vote only when they provide the voter id in the pooling booth. The major drawback of voting is bogus votes. To overcome those we use many authentication standards.

Aadhar is unique identification authority of India which every personal should be enrolled in it. For every governmental action performed it requires the Aadhar card provided with biometric authentication which assures that the person has all the right to perform the required action. The proposed process reduces the whole man power in the polling booth and also reduces the man power used in the counting process. All the action performed is automated and can also be monitored whenever needed. An algorithm is used for encryption and decryption which ensures the security for the votes. 
International Journal of Trend in Scientific Research and Development (IJTSRD) ISSN: 2456-6470

\section{LITERATURE REVIEW}

\section{1) Electronic voting using near field communication}

\section{Authors-Syed Mahmud hasam}

In recent times there has been a decline in the confidence of common people over electronic voting machines (EVMs). More anticipated than what the reality actually is, today's automated vote casting methods have faced immense controversy related to being vulnerable to hacking and questions have been raised about their transparency and security. This paper proposes the design and development of a novel tamper resistant electronic voting system that aims to mitigate the recurring issues and flaws of existing voting machines of today. To elucidate the system in brief, multiple layered verification process would be carried out on a potential voter by the means of fingerprint recognition and a Near Field Communication (NFC) smart card entry in order to authenticate his or her identity. Subsequently, the person would cast the vote by pressing a button corresponding to a particular candidate which would be recorded in the system providing the vote caster a visual confirmation. The final vote would then be printed out spontaneously onto a ballot box using a POS (Point of Sales) printer for an added level of validation. This system not only prevents multiple vote casts, but also eliminates the discrepancies that commonly arise with a person claiming not to have voted, whereas his or her name is present in the list of vote casters. The project is an incremental extension of a previous research.

\section{2) RF-ID match-on-card sui generis}

\section{Authors-Md.Tahmid Rashid}

Elections casts an ennobling influence on the minds of people and forms the prominent feature of our country-India, in which every individual participates vigilantly and the populace remains the sovereign power. The world has been experimenting with diverse technologies to conduct controversy free elections, to fulfill the elementary needs of the people. It should be taken into account that no elector should be disenfranchised from their voting rights. Our main objective is to design a model to provide equitable elections. In this project, the baseline information stored in the RFID tag provides topical reference data that mediate intensive computational prerequisite, it also provides easy match-on-card sui generis feature and meet the constraint that only eligible voters can cast their vote. Moreover, added tier of security is enforced as bio-metrics. It is seen that there is a noticeable diminution in the turnout rate of voters, especially the youth. To foster participation among all demographic groups, our design looks into the multiple dimensions and notes all security requirements and provides an inexpensive solution based on RF-ID, GSM and fingerprint module in quest for election legitimacy.

\section{3) Smart card using proteus professional software}

\section{Authors- MD.ShadmanSakib Chowdhury}

In improved electronic voting machine using a microcontroller and a smart card is presented. The identity control that was done manually is eliminated and replaced by a smart card. It also saves the elector's card number, number of electors, and the voting results while ensuring anonymity. The results are only accessible for the administrator card. The simulation is done using Proteus Professional Software V7. Microcontrollers are programmed in assembly language under MPLAB IDE software V.8.56.

\section{4)Direct recording electronic ic card reader}

Authors - Md. KhalilurRhaman

There have been several studies on using computer technologies to improve elections and these studies lead to widespread adoption of "direct recording electronic" (DRE) voting systems in recent years. In an electronic-voting system, voters go to their voting places and prove that they are allowed to vote there by presenting an ID card with signet. After this, the voter is given a token that allows them to vote for their candidates of choice at a voting machine. When the voter's selection is complete, DRE systems with typically present a summary of the voter's selections, giving them a final chance to make changes. Subsequent to this, the ballot is cast and voter shall return the given token to ballot box and leave voting place.In this research, we design and implement an e-voting system that provides DRE capability. Our e-voting system is equipped 
with an IC card reader and a touch-panel LCD. Cost and security are the two most important facts to the success of our e-voting system. Low cost on the token is obtained by selecting reusable contactless IC card as voting token. Security of our e-voting machine is obtained not by secrecy, but by openness and secure coding of software.

\section{EXISTING SYSTEM:}

- In developing countries like "INDIA" the election commission follows manual voting mechanism which is done by electronic voting machine. This machine is placed in the poll booth center and is monitored by higher officials. due to some illegal activities the polling center are misused and people's vote to right has been denied.

- The automated voting systems are developed before some years ago. The existing systems have only been approved in developed countries. That too, not in all developed countries. Because the security has not yet been fully preserved. We moved onto automation mainly to rely on security.
Hospitalized person can also be able to vote by using GSM module with his Aadhar card number.

\section{ADVANTAGES OF PROPOSED SYSTEM:}

- Secure voting with unique identity.

- Improved performance and efficiency

- Better in scalability when compare with existing systems

\section{ARCHITECTURAL DIAGRAM:}

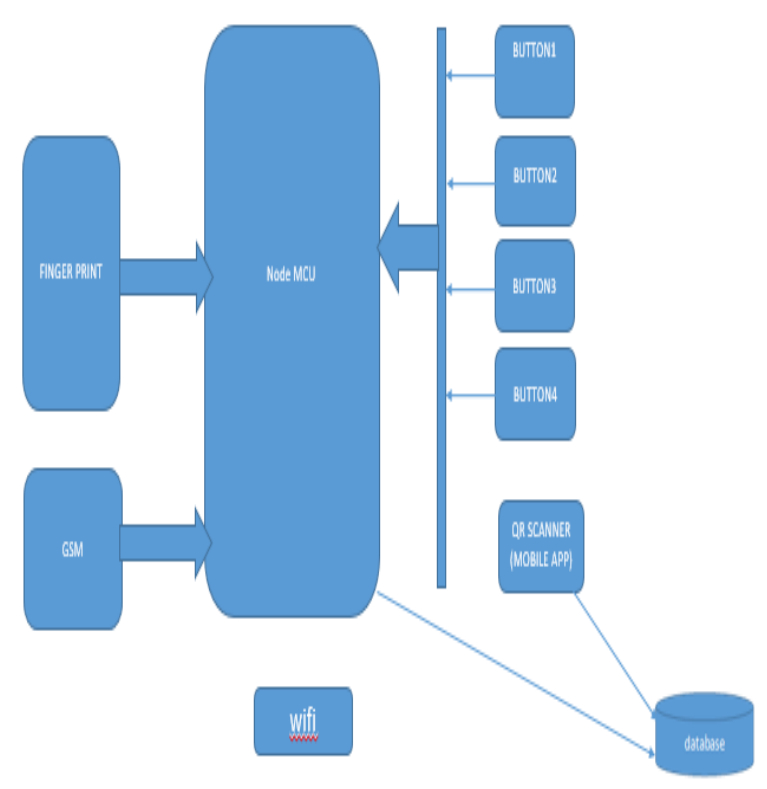

\section{DISADVANTAGES OF EXISTING} SYSTEM:

Lack of Security while voting.

Poor performance and efficiency compared with proposed system.

Existing system has scalability problem.

\section{PROPOSED SYSTEM}

$>$ This system proposed a secure online voting system by utilizing the concept of biometric

$>$ Our Proposed System is a finger-print based Application that enhances our country with a better voting system to ensure $100 \%$ voting

$>$ Since the existing voting system is not having high security our project will overcome this major drawback.

\section{Conclusion}

We proposed an efficiently implementable version of an algorithm is designed to provide a secure data and to provide a trustworthy election amongst the people of the democracy. The percentage of the voting will be increased by utilizing the mobile application. In future Aadharcard is the most needed for a person identity hence deploying a election process using it is highly recommendable. The time consumption for casting a vote is reduced comparatively when compared with the current scenarios and outperforms other existing secure data sharing schemes interms of performance and scalability.

\section{REFERENCES}

1) Benaloh, J.\&Tuinstra, D. (1994) "Receiptfree Secret-Ballot Elections", In Proceedings of the 26th ACM Symposium on Theory of Computing (STOC'94), Montreal, Canada. 
2) APPENDIX 2J, Experience of electronics voting overseas.

THE

POLICYINSTITUTE,TRINITY

COLLEGE DUBLIN.Dr.Kenneth Benoit ,Department of Political Science TCD.

3) Brenock, M. (2004) Cabinet to press ahead on e-voting in EU and local polls. The Irish Times.

4) California Secretary of State Ad Hoc Touch screen Voting Task Force Report

5) Caltech-MIT. (2001) Voting: what is, what could be. Cal Tech-MIT Voting technology Project Report

6) Cetinkaya, O. \&Cetinkaya, D. (2007) "Towards Secure E-Elections in Turkey: Requirements and Principles".

7) Chaum, D. (1981) "Untraceable Electronic Mail, Return Addresses, and Digital Pseudonym.

8) Chaum, D. (1982) "Blind Signatures for Untraceable Payments".

9) Chaum, David (2000) Secret-Ballot Receipts and Transparent Integrity.

10) Cranor, L. \&Cytron, R. (1997) “census: A Security-Conscious Electronic Polling System for the Internet". 